\title{
IoT-based Framework for Coordinating Smart Home
}

\author{
${ }^{1}$ Azlina Ahmadi Julaihi ${ }^{2}$ Nur Hazierah Mazlan ${ }^{3}$ Abdul Rahman Mat \\ ${ }^{1,2}$ Department of Network Computing, Faculty of Computer Science and Information Technology, \\ Universiti Malaysia Sarawak, 94300 Kota Samarahan, Sarawak, Malaysia \\ ${ }^{3}$ Department of Software Engineering, Faculty of Computer Science and Information Technology, \\ Universiti Malaysia Sarawak, 94300 Kota Samarahan, Sarawak, Malaysia \\ email: ajazlina@unimas.my, ${ }^{2}$ hazierah71@gmail.com, ${ }^{3}$ marahman.unimas.my
}

Date received: 30 November 2020

Date accepted: 12 May 2021

Date published: 1 November 2021

\begin{abstract}
IOT RFID Door Open Notification for Homestay is a system that focuses on the use of RFID as a door lock and keeps track the database of Homestay's guest check-in and check-out time data. By implementing this project, the homestay owner can view and update the check-in and check-out time of their guest whenever required. MySQL will be used in this project for database support and logging the Homestay Web-based System. In this paper, a new framework with Radio Frequency Identification technology (RFID) applied to homestay door lock is exposed. In order to validate the designed framework, an experiment to configure the speed capture by the RFID reader was carried out.
\end{abstract}

Keywords: Homestay, RFID, Radio Frequency Identification.

\section{Introduction}

Internet of Things home automation has rapidly increased and become a world trend global companies such as Google and Amazon take the opportunity of this growing market by innovating and producing various IoT based products for example Google Home and Amazon Alexa. According to (Patel, 2020), the global market for smart home automation is expected to reach $\$ 40$ billion by 2020 with many functions to offer, not only to reduce the cost and energy but also increase the productivity since these devices are interconnected. Nowadays smart home services are not limited to be applied to a home for a basic function but also commercialize and widely entering the accommodations market.

The conventional method such as manual booking system or energy resources management are still being used nowadays however for a grown-up business for example a big company, these methods are not relevant thus IOTs implementation can be a medium to solve the problems. In this paper, IoT-based Framework for Coordinating Smart Home is proposed and apply on Homestay. Ramaraj et al. (2019) in his thesis has conducted over 100 sample of surveys to analyze the reasons people choosing Homestay which resulted to "authentic socio-cultural experience", "security and warmth of the home", "economic and cheap price", "environmental preservation" and "Educational knowledge".

While hotels provide front counters, Homestay uses different approaches to coordinate the check-in and checkout details with the host and communication is vital to make sure the house or room booking is reserved. Homestay hosts usually will exchange the homestay keys in person, leave them in a lockbox, or let a neighbor meet a visitor and time-consume to secure the booking increases. In this paper, RFID tags will be used to unlock the door replacing the conventional method. IOT RFID Door Open Notification for homestay is a system that focuses on integrating RFID with the door lock to keep track of the database of homestay's guest check-in and check-out time data. The proposed system requires the RFID tag to be registered in a web-based system first to allow the user to use the tag. Installation of RFID Tag Reader that is connected to Wi-Fi is needed in order to transmit in real-time information of check-in and check-out time of the homestay guest. This paper, Section II presents the related works in IoT. In Section III, this paper will present the proposed framework of homestay based on RFID. Section IV presents the experimental settings, results and analysis based on the case study. Finally, the conclusion and the future work are presented in Section V. 


\section{Related Work}

Li et al. (2018) proposes a flooding warning system based on RFID tag array for energy facilities such as power stations. The main focus of this proposed system is to study the Received Signal Strength Indicator (RSSI) of the power present in a received radio signal. Pedraza et al. (2016) proposed road traffic monitoring based on RFID. Traffic congestion is a very common condition that is not limited only in urban but also rural areas. The RFID framework in Intelligent Transportation Systems (ITS) is proposed to get information of a city and the variables involved flow and density, speed, Headway and others. A simple tag is attached to the vehicle reading that senses the car passing by a specific spot. Following this, the reader ensures the tags are part of the program and sends the tag information to a remote server for saving and processing.

The WHO estimates that approximately $90 \%$ of people with visual impairment in the world are living in countries with poor and middle income (Blindness and vision impairment, 2020). Li et al. (2018) in his paper proposed the RFID cane system with posture effect control and it is an alternative for a cheaper mobility of these people. IoT-based Framework for Coordinating Smart Home is proposed based on RFID. The Homestay owner can optimize their homestay management by the real-time check-in and check-out data of their guests and can keep track the database in a proper database management system. There are some important features that the existing systems do not have including notification system and website monitoring designed for homestay. Table 1 shows the different aspect between the previous systems and the proposed system.

Table 1: The differents aspect between the previous system and the proposed system.

\begin{tabular}{|c|c|c|c|c|}
\hline Paper & $\begin{array}{l}\text { A Flooding Warning } \\
\text { System based on } \\
\text { RFID Tag } \\
\text { Array for Energy } \\
\text { Facility }\end{array}$ & $\begin{array}{l}\text { RFID framework } \\
\text { for intelligent traffic } \\
\text { monitoring. }\end{array}$ & $\begin{array}{c}\text { Wireless Control for } \\
\text { Vision Impaired } \\
\text { Based on } \\
\text { Posture Effect of } \\
\text { UHF RFID Cane }\end{array}$ & $\begin{array}{l}\text { Proposed System } \\
\text { (Door Open } \\
\text { Notification System } \\
\text { for Homestay) }\end{array}$ \\
\hline Domain & $\begin{array}{c}\text { Flood Warning } \\
\text { System }\end{array}$ & Traffic Monitoring & Healthcare & Accommodation \\
\hline Objectives & $\begin{array}{l}\text { To study the Received } \\
\text { Signal Strength } \\
\text { Indicator (RSSI) of } \\
\text { the power present in a } \\
\text { received radio signal }\end{array}$ & $\begin{array}{c}\text { Monitor vehicular } \\
\text { behavior inside the } \\
\text { National University } \\
\text { of Colombia } \\
\text { campus using a } \\
\text { RFID platform }\end{array}$ & $\begin{array}{c}\text { To improved mobility } \\
\text { for visually impaired } \\
\text { person. }\end{array}$ & $\begin{array}{c}\text { Allow the MZR } \\
\text { Homestay's owner to } \\
\text { coordinate the check- } \\
\text { in and check-out } \\
\text { details of their guest } \\
\text { by using RFID that } \\
\text { connect to the Web- } \\
\text { based system. }\end{array}$ \\
\hline $\begin{array}{c}\text { Technology } \\
\text { Based }\end{array}$ & RFID & RFID & RFID & RFID \\
\hline Connectivity & N/A & Cellular Network & N/A & Wi-Fi \\
\hline \begin{tabular}{c|} 
Data \\
Management \\
Availability
\end{tabular} & $\begin{array}{c}\text { Data from the tag will } \\
\text { be stored } \\
\text { into database. }\end{array}$ & $\begin{array}{l}\text { The tag } \\
\text { information is sent } \\
\text { to a remote } \\
\text { platform to be } \\
\text { stored and } \\
\text { processed. }\end{array}$ & $\begin{array}{l}\text { The reader will } \\
\text { detect the tag and } \\
\text { send signal to the } \\
\text { host the computer. }\end{array}$ & $\begin{array}{l}\text { Data from the tag will } \\
\text { be stored } \\
\text { into database and can } \\
\text { be monitored through } \\
\text { homestay website. }\end{array}$ \\
\hline $\begin{array}{c}\text { System } \\
\text { Drawback }\end{array}$ & $\begin{array}{l}\text { The tag array cannot } \\
\text { be detected } \\
\text { when the distance } \\
\text { reaches around } 30 \mathrm{~cm}\end{array}$ & $\begin{array}{c}\text { High error rate, } \\
\text { there are readings } \\
\text { that are lost and are } \\
\text { not recognized by } \\
\text { the system }\end{array}$ & $\begin{array}{c}\text { The data channel } \\
\text { between the tag and } \\
\text { the } \\
\text { reader are mostly } \\
\text { disturbed by } \\
\text { environmental noise }\end{array}$ & $\begin{array}{c}\text { The maximum } \\
\text { distance for the RFID } \\
\text { reader to detect the } \\
\text { passive RFID card is } \\
4.0 \mathrm{~cm}\end{array}$ \\
\hline
\end{tabular}

\section{Framework}

\subsection{Overall Framework}

The framework was validated by implementing the RFID based door lock system to monitor the check-in and check-out time on homestay guest. Figure 1 shows an overview of the system architecture, that includes the mobile client and the cloud server.

Figure 1: The system architecture of the RFID on door lock system.

Based on Figure 1, the system architecture has summaries the project system. The RFID Tag has a unique identification code that can be read by RFID Reader. The homestay administrator needs to register the RFID 
Tag to the database in order to implement a RFID Tag with a unique Tag ID. The Tag ID will be kept in the database and now the tag cannot be easily duplicated. The RFID Reader requires the RFID Tag to be scanned in order to verify the valid tag for the guest to enter the house. If the tag is valid, the door lock will be opened. RFID uses radio waves to communicate with readers.

When a reader picks up these waves, it converts them into digital data that identifies the object that contains the tag. The RFID Reader and door lock will be connected with NodeMCU that act as a microcontroller and before starting the project, the Arduino environment must be set up. NodeMCU will be connected to the computer via USB cable. Arduino IDE can be downloaded at www.arduino.cc website. The Arduino IDE supports $\mathrm{C}$ and $\mathrm{C}++$ languages. When the NodeMCU is linked to the internet over Wi-Fi, the system will be online. We will now connect the hardware with the software and keep the data in a web-based system. After all the hardware and software setup are done, as the result when the homestay's guest check-in and check-out the homestay, the time will be recorded into the database system. The homestay's owner now can easily track and monitor the data by using the homestay Web-based system. In the web-based system there are several admin modules that have been created such as 'Admin can Sign Up an account of the system', 'Admin can Login into the system', Admin can Logout from the system, Admin can register the RFID Tag into the system, Admin can monitor and update the homestay check-in and check-out details (Edit, Update, Delete), Admin can search all the records based on the booking dates.

\subsection{Components Involved}

In order to perform the experiments, the hardware that are being used are NodeMCU Lua V3 ESP8266, MFRC522, RFID Tag and Tag, Breadboard and Male-to-Male Wire. The NodeMCU Lua V3 ESP8266 is a microcontroller that will be a medium to interpret the hardware component to be combined together with software. In this project, Passive RFID tags are used and it is completely depends on the power sources (electromagnetic energy) of the RFID reader. These radio waves charge up the coiled antenna present in the passive tags. After being provided with charge, the power source moves from antenna to Integrated Circuit (IC) thus powering the chips which then send back the signal to the radio frequency system. This overall process is known as backscatter which is detected by the reader and information is interpreted out of it (Hoffman, n.d).

\subsection{Operation Flowchart}

Flowchart is an indicator for the flow of programming programs and it is easy to understand how the software function is described in a flowchart word. IOT RFID Door Open Notification for homestay flowchart in Figure 2 shows how the whole system process. The device begins with the presence of power supply of RFID reader. User need to swap the RFID tag or tag that will be given by the homestay owner to check-in and check-out the homestay. There are two different types that are passive, semi-passive and active RFID tag. In this project, passive tag is use to access the door lock and it relies fully on the radio waves that coming from the RFID reader for the source of energy. One of the advantages to use a passive tag is it is economical among all RFID tag types, it comes in smaller in size and low noise. We do not need to use the active RFID tag as the RFID readers do not require a long read range. The RFID Reader will read the RFID tag and if there is no presence of the RFID tag, the program will start over and back to initiate state. If the tag is presence, the RFID Reader will read the tag and validate it match. The door lock will reject and will not open if the RFID Reader not validates the tag. If the validated tag is presence, the homestay door lock will be opened and the homestay guest now can check-in the homestay. Both check-in and check-out time of the homestay will be written into homestay database and be displayed in the homestay web-based system. 


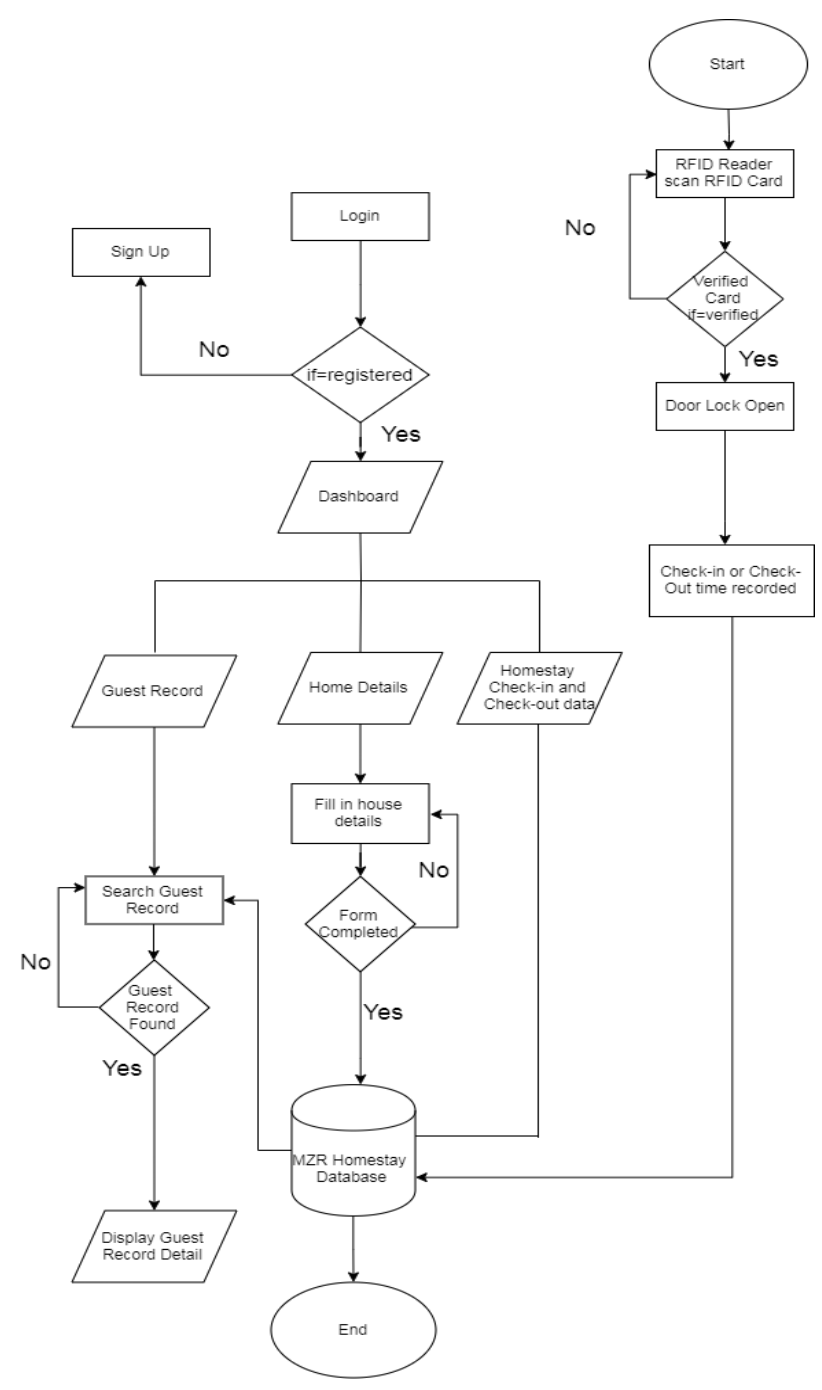

Figure 2: The flowchart of the RFID based door lock system to monitor the check-in and check-out time on homestay guest.

\subsection{Experimental Settings}

The software part involves Arduino IDE to program the instructions from the hardware and connect it to the web based, PHP My Admin to store all the databases that are needed for this proposed project, Hypertext Markup Language (HTML) which is the standard markup language for Web pages. The internet bandwidth are fixed on $100 \mathrm{~Kb}$ per second and controlled by using NetBalancer software to make sure the speed limit for various distance are same. The next step following completion of the hardware configuration process will be the development of the proposed homestay website application. The development of website application is necessary for the homestay admin as a medium to display and monitor all the records from the RFID reader. Arduino IDE will be integrated to homestay website.

IOT RFID for the homestay uses local server for the system development and for this project, XAMPP is used. There are a few reasons people used XAMPP as a platform to store the databases needed especially in web applications. XAMPP allows people to install Apache, MySQL and PHP on the laptop. The installation is easy and most importantly it is free and suitable in creating website applications because it let people test the websites before releasing it to the web server. HTML, CSS and Javascript work together and are used in designing the user interface and display of the website. The main function that needs to be displayed in the website is the check-in and check-out time of the homestay guest. 


\section{Result and discussion}

As the proposed system is concerned with providing the user with a precise contextual message, it is therefore essential to validate whether the correct tag's information such as Tag ID, Guest Name, Phone Number and House Number are registered on databases in order to give permissions to the homestay guest to unlock the door so that they can enter the house. An experiment has been conducted in order to analyze the capability of RFID to capture the information from the tag. The findings obtained in this section are therefore interpreted and evaluated on: 1) the speed at which the RFID reader captures information on the RFID tag VS Distance.

1) The results of the speed at which the RFID reader captures information on the RFID tag VS Distance are displayed in Figure 3.

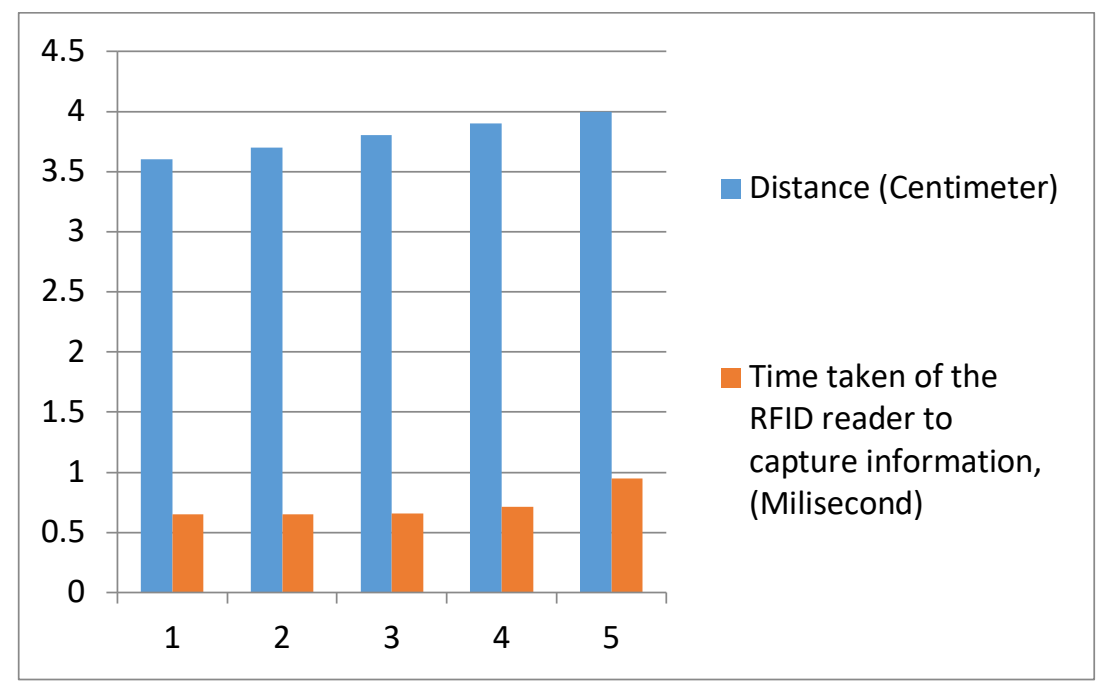

Figure 3: The results of the speed at which the RFID reader captures information on the RFID tag VS Distance.

The platform was tested by measuring the time taken by the RFID reader to collect information on the RFID tag VS Distance. Figure 3 shows the effects of the speed at which the RFID reader collects information on the RFID tag VS Distance d. There are five distances are calculated in this experiment, and the results in Figure 3 show the average time taken for the RFID reading. Based on the experiment, the maximum distance for the RFID reader to detect the passive RFID tag is $4.0 \mathrm{~cm}$ and the difference in time taken for the RFID reader to collect information between the maximum and the minimum distance is 0.3010 milliseconds. This indicates that and when the distance between the RFID reader and the passive RFID tag is increased, the time taken by the RFID reader to capture the tag information is also increased.

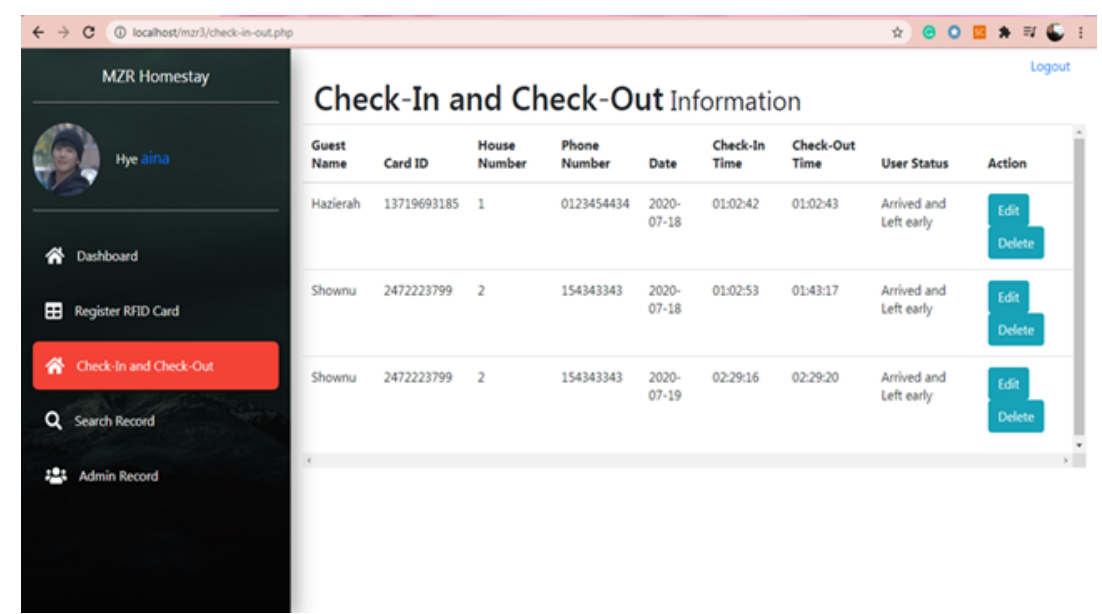

Figure 4: The Check-In and Check-Out Page on homestay web-based system. 
Before the guest check-in into the homestay, the homestay admin needs to register the RFID card at "Register RFID Card" page. The card's information such as Card ID, Guest Name, Phone Number and House Number then will be stored in the databases in order to give permissions to the homestay guest to unlock the door so that they can enter the house. Figure 4 shows the guest details with their check-in and check-out status. In this project, there are two conditions that affect the status of the guest's arrival time and departure time, so the time taken for the RFID reader to send the databases is important as the check-in and check-out time decides the 'user status' whether to check-in or check-out at the correct time as the RFID tag has been scanned. The check-in time for the homestay must be at $2 \mathrm{p} . \mathrm{m}$. or at $2 \mathrm{p} . \mathrm{m}$. and the check-out time must be before or at $12 \mathrm{p} . \mathrm{m}$. If the information speed at which the RFID reader collects information on the RFID tag has been delayed, it will result in inaccurate information about the check-in and check-out period that will be shown on the homestay website and, in the worst case, the homestay guest will have to pay an extra fee because the 'user status' appears to have reached the limit and overstay.

\section{Conclusions}

In this project, passive RFID tags are used to collect the house details and information. Despite all the benefits such as Passive RFID is economical among all RFID tag types, it comes in smaller in size and Low noise, no noise passive RFID tags also comes with their limitations. Passive RFID tags can are completely dependent on the power sources (electromagnetic energy) of RFID reader. These radio waves charge up the coiled antenna present in the passive tags. Next, this tag also read short distance range and for this project the maximum range that the RFID reader can read is only $4.0 \mathrm{~cm}$ between the readers. RFID tags do not require line-of-site (LOS) for it to be read by the reader however it also depends on the material and if metal objects block the LOS, is blocking the line-of-sight, the system performance will be degraded and this can still be a serious problem. For future recommendation, on the perspective of the RFID itself, high range RFID can be used in order to increase its efficiency, reliability and effectiveness. The distance also will be increased in range of a reader which will make the tag be easier to read.

\section{Acknowledgements}

The author would like to acknowledge all the associated personnel, comment and suggestions that contributed in the completion of this research.

\section{References}

Blindness and vision impairment. (2020, October 8). Didapatkan October 20, 2020, daripada https://www.who.int/: $\quad$ https://www.who.int/news-room/fact-sheets/detail/blindness-and-visualimpairment

Changhe, L., Keng-Weng, L., \& K. Tam. (2018). A Flooding Warning System based on RFID Tag Array for Energy Facility. 2018 IEEE International Conference on RFID Technology \& Application (RFID-TA). Macau, China: IEEE.

Chang-He, L., Keng-Weng, L., \& Kam-Weng, T. (2018). A Flooding Warning System based on RFID Tag. 2018 IEEE International Conference on RFID Technology \& Application (RFID-TA). Macau, China: IEEE.

Hoffman, J. (t.t). Understanding Passive RFID Tags. Didapatkan October 21, 2020, daripada https://wisdomplexus.com/: https://wisdomplexus.com/blogs/passive-rfid-tags/

Patel, R. (2020, June 10). IoT and home automation: What does the future hold? Didapatkan October 6, 2020 , daripada www.iot-now.com: https://www.iot-now.com/2020/06/10/98753-iot-home-automation-futureholds/

Pedraza, C., Silva, D., \& Arevalo, A. (2016). RFID framework for intelligent traffic monitoring. Euro American Conference on Telematics and Information Systems. Cartagena, Colombia: IEEE.

S., K., Ramaraj, K., \& Thangasamy, M. (2019). A Study on Tourist's Perception about Homestay Services at Coorg. Journal of Emerging Technologies and Innovative Research (JETIR), 1-7.

Sanghera, P. (2007). RFID+ Study Guide and Practice Exams. 